\section{Avaliação de intervenção educativa sobre aleitamento materno dirigida a agentes comunitários de saúde}

\section{An evaluation of an educational intervention regarding maternal breastfeeding carried out by community health visitors}

Maria Cristina Heinzle da Silva Machado 1

Juliana da Silva Oliveira 2

Cristina Maria Garcia de Lima Parada 3

Sonia Isoyama Venâncio 4

Vera Lúcia Pamplona Tonete 5

Maria Antonieta de Barros Leite Carvalhaes 6

- Secretaria Municipal de Saúde de Botucatu. Botucatu, SP, Brasil. 2 Hospital das Clínicas. Faculdade de Medicina de Botucatu. Universidade Estadual Paulista "Júlio de Mesquita Filho". Botucatu, SP, Brasil.

3,5,6 Departamento de Enfermagem. Faculdade de Medicina de Botucatu. Universidade Estadual Paulista "Júlio de Mesquita Filho". Anexo $\mathrm{H}, 1^{\circ}$ andar. Distrito de Rubião Júnior, s.n. Botucatu, SP, Brasil. CEP 18618-970. E-mail: carvalha@fmb.unesp.br 4 Instituto da Saúde. Secretaria Estadual de Saúde de São Paulo. São Paulo, SP, Brasil.

\section{Resumo}

Objetivos: avaliar ação educativa visando à capacitação de agentes comunitários de saúde em promoção e apoio ao aleitamento materno.

Métodos: estudo do processo e adequação de intervenção, com comparação de conhecimentos e práticas de 54 agentes, antes e dois meses após a ação. A intervenção, quatro oficinas teórico-práticas com oito horas cada, fundamentou-se em principios da Educação Crítico-Reflexiva e em dois cursos de capacitação de equipes de maternidade. Os resultados foram expressos pelas diferenças dos escores médios de conhecimentos, práticas e total, adotandose $p<0,05$ como nivel crítico.

Resultados: houve aumento do escore médio de conhecimentos (21,0 para 26,6; $p<0,001)$ e de escores de conhecimentos classificados como bons (37,0\% para $88,8 \%, p<0,001)$. Não houve mudanças no escore de participação dos agentes em específicas ações de saúde, como grupos. $O$ efeito da intervenção mais apontado pelos agentes foi "sentir-se mais aceito e em melhores condições de participar da equipe multiprofissional em situações envolvendo cuidados com crianças". Mais da metade relatou melhora na qualidade e quantidade das orientações prestadas nas visitas domiciliarias.

Conclusões: a intervenção tem efeitos positivos sobre conhecimentos e a prática dos agentes junto às famílias, mas não promove aumento da sua participação em específicas ações de saúde.

Palavras-chave Aleitamento materno, Agente comunitário de saúde, Capacitação em serviço, Estudos de intervenção
Key words Breastfeeding, Community health agent, In-service training, Intervention studies 


\section{Introdução}

Nos últimos anos, têm-se observado tendência favorável das taxas de aleitamento materno exclusivo (AME) e de aleitamento materno (AM) no Brasil,1 fruto de três décadas de atuações bem sucedidas, com destaque para a implantação da Iniciativa Hospital Amigo da Criança. ${ }^{2} \mathrm{Na}$ atualidade, para a obtenção de novos ganhos, tem sido preconizado mais investimento na capacitação de profissionais da atenção básica em promoção, apoio e manejo do aleitamento materno. ${ }^{3}$

A Estratégia Saúde da Família (ESF), pelos seus princípios e forma de organização do processo de trabalho, reúne condições favoráveis à atuação positiva sobre os indicadores de AM. Evidencia-se a prática do cuidado familiar ampliado, efetivada por meio do conhecimento do território, bem como da estrutura, desenvolvimento e funcionabilidade das famílias e a proposição de ações intersetoriais, voltadas à promoção da saúde. 4 No âmbito da equipe multiprofissional que atua sob a ESF, acredita-se que o agente comunitário de saúde (ACS) constitui elemento em posição privilegiada para a implementação de ações nesta área, devendo ser capacitado para tal.

A atual proposta ministerial prevê que atividades relativas ao cuidado façam parte do roteiro de atuação do ACS nos espaços de vida cotidiana da criança (domicílio e instituições de educação infantil), para atuação na prevenção de doenças, promoção da saúde e identificação de necessidades especiais em tempo oportuno, tais como: alteração no processo de crescimento e desenvolvimento, desvios na alimentação e imunização atrasada, de forma a viabilizar a pronta abordagem da criança com algum sinal de risco ou perigo. 5

Nas unidades de saúde, nos domicílios e coletividade, esses profissionais estendem o acesso às ações e serviços de informação e promoção social e de proteção da cidadania, além de participar da orientação, acompanhamento e educação em saúde. ${ }^{6}$

Em 2007, ano de realização do presente estudo, não foram encontradas publicações sobre cursos específicos para capacitação de ACS para a promoção e apoio ao aleitamento materno. Posteriormente, uma estratégia educacional concebida dentro da iniciativa unidade básica amiga da amamentação foi avaliada, mediante ensaio aleatorizado e controlado conduzido em unidades de saúde da família de Montes Claros (MG), com resultados positivos sobre a duração do aleitamento materno exclusivo. Embora não tenham sido apresentadas avaliações formais do processo, os autores apontam que a participação dos agentes comunitários de saúde foi fundamental para o sucesso da iniciativa, confirmando o potencial desta categoria como promotores do aleitamento materno. ${ }^{7}$

Também merece menção a iniciativa Rede Amamenta Brasil, apresentada pelo Ministério da Saúde brasileiro em 2008/2009, com foco na capacitação de profissionais da atenção básica e na organização local das ações de promoção e apoio ao aleitamento materno. Esta iniciativa representa o reconhecimento do papel da atenção básica para a obtenção de novos ganhos na duração do aleitamento materno. 8

Entendendo que a atenção básica à saúde constitui espaço onde ações inovadoras poderão gerar avanços nos índices de amamentação nos municípios brasileiros e pressupondo que os ACS, devidamente preparados, possam contribuir neste sentido, o presente estudo objetivou avaliar uma intervenção educativa sobre promoção e apoio ao aleitamento materno voltada aos ACS de um município do interior paulista.

\section{Métodos}

Trata-se de estudo da adequação de intervenção educacional sobre AM, incluindo avaliação de efeitos, na visão dos ACS. A avaliação envolveu a comparação dos conhecimentos e práticas dos ACS antes e dois meses depois do encerramento da ação educativa (AE), sendo utilizado controle histórico.

A ação educativa, no contexto da educação permanente em saúde, foi inspirada em princípios da educação crítico-reflexiva. Em linhas gerais, segundo esse referencial pedagógico, os educandos são reconhecidos como sujeitos ativos de seus próprios conhecimentos, construindo significados e definindo sentidos e representações da realidade de acordo com suas experiências e vivências. O eixo central desse referencial consiste no pensamento crítico/produtivo e na atividade consciente/intencional dos educandos na resolução dos problemas encontrados na realidade. 9,10

Organizou-se intervenção de 32 horas, na forma de oficinas de cunho teórico-prático, desenvolvida em quatro encontros semanais presenciais, consecutivos, de oito horas cada, permeada por atividades programadas a serem realizadas em campo (unidades de saúde da família e domicílios), durante os meses de setembro e outubro de 2007.

Para o estabelecimento do conteúdo a ser abordado, distribuição da carga horária da $\mathrm{AE}$ e seleção da estratégia de ensino, os resultados da avaliação inicial de conhecimentos e práticas dos ACS foram 
considerados. Foram incluídos conteúdos teóricopráticos sobre AME, AM e alimentação complementar; problemas mais frequentes na prática da amamentação; rotinas e práticas para proteção, promoção e apoio ao AM na atenção básica e na atenção domiciliar; e possibilidades de atuação do ACS no apoio às gestantes, mães e suas famílias nos processos de amamentação. Como método de ensino, valorizou-se principalmente a discussão participativa focada na solução de problemas/dificuldades vividos pelas mães e reportados/percebidos aos/pelos ACS no cotidiano do trabalho e nas suas experiências pessoais em relação ao AM, sendo que nas atividades propostas houve a preocupação de se ater ao limite da competência técnica e legal do ACS. 6

O estudo foi realizado em Botucatu, município com cerca de 121.000 habitantes, 11 localizado na região centro-sul do Estado de São Paulo, onde os indicadores de aleitamento mais recentes disponíveis para o município foram: 29,6\% de AME em menores de seis meses e $61,7 \%$ de AM em menores de um ano,12 em 2004. Ressalta-se que nenhuma das três maternidades do município detinha, na época, o título de "Hospital Amigo da Criança".

Em 2007, quando se iniciou esta investigação, aproximadamente $25 \%$ da população estava coberta por unidades de saúde da família, com um total de 10 equipes implantadas e 71 ACS contratados. Todos os agentes foram convidados a participar do estudo, não havendo recusas. Porém, em decorrência de férias, licenças e demissões, 68 responderam à avaliação pré-intervenção, 65 compareceram ao início da intervenção e 62 participaram da avaliação de processo. Dois meses após o término da intervenção, foram encontrados em atividade e entrevistados 58 ACS envolvidos no estudo, sendo excluídos quatro que não participaram de todos os momentos da intervenção, resultando em 54 ACS que participaram das três etapas: avaliação pré-intervenção, intervenção e avaliação dois meses após a intervenção.

Para a coleta dos dados, prévia e posterior à intervenção, foi elaborado um questionário sobre conhecimentos relativos ao AM e sobre a participação dos ACS em práticas/ações de promoção e apoio ao AM junto às famílias, tomando por base instrumentos com propósitos semelhantes adotados por outros estudos, particularmente os de Becker ${ }^{13} \mathrm{e}$ Ciconi et al. ${ }^{14}$ Após ser apreciado por um comitê de expertises em AM e submetido à pré-teste, com nove ACS de outro município, o questionário foi revisado e sua consistência testada, alcançando-se índice bruto final de alfa-Cronbach de 0,59, considerado aceitável. O questionário incluiu questões relativas a características pessoais e profissionais dos agentes e outras focadas em captar a sensibilização destes para o tema AM. Abordaram-se conhecimentos da fisiologia da lactação e manejo da amamentação; capacitação prévia em relação ao AME e AM e sobre o desenvolvimento ou não de práticas relacionadas à promoção, proteção e apoio ao $\mathrm{AM}$ junto às famílias da área de atuação do ACS.

A aplicação do questionário foi conduzida por dois entrevistadores treinados (10 horas de treinamento, com simulação), sendo as entrevistas previamente agendadas conforme a disponibilidade dos ACS e realizadas nas unidades de saúde da família onde trabalhavam, em local que garantiu privacidade e conforto. Os entrevistadores não participaram da $\mathrm{AE}$ e não tinham prévio contato profissional ou pessoal com os ACS.

Para análise dos dados, os questionários foram revisados e digitados em banco do programa Excel 6.0 , sendo conferidos cerca de $5 \%$ dos mesmos, sorteados, para verificação da qualidade da digitação e correções. Seguiu-se a análise de consistência e o processamento das frequências de respostas de todas as questões, com o programa SPSS 12.0. Todas as questões relativas a conhecimentos e práticas/ações foram, posteriormente, classificadas em adequadas ou inadequadas, de acordo com gabarito fundamentado em dois cursos de capacitação de equipes de maternidade em AM.15,16 As distribuições de freqüências de ACS, segundo respostas adequadas ou inadequadas, antes e após a capacitação, foram computadas e comparadas. Nessa comparação, foi empregado o teste qui-quadrado.

Para sintetizar a avaliação das mudanças em conhecimentos e práticas foram criados escores de conhecimentos (0-31), de práticas (0-20) e total (051) comparados em termos de valores médios, antes e após a capacitação, pelo teste $t$ de Student para amostras pareadas. Os escores também foram categorizados em três níveis: bom ( $\geq 75 \%$ de acertos), regular $(\geq 50 \%$ e $<75 \%$ de acertos) e ruim $(<50 \%$ de acertos), sendo a comparação, antes e após, feita pelo teste qui-quadrado. Em todas as análises, adotou-se $p<0,05$ como nível de significância estatística.

A avaliação dos efeitos da AE na visão dos ACS, realizada dois meses após seu encerramento, foi investigada com duas questões abertas: "O que mudou, em sua prática diária de trabalho, após o curso sobre aleitamento: a) Quando você está junto com a sua equipe de PSF? b) Quando você está fazendo suas visitas na comunidade?" As respostas foram digitadas na íntegra e categorizadas segundo o método de análise de conteúdo, proposto por 
Bardin, 17 seguindo o modelo instrumental de abordagem quantitativa, na vertente temática. Deste modo, foi possível recortar, a partir do conteúdo das mensagens obtidas, as unidades de registro, classificando-as por núcleos de sentido correspondentes aos temas delimitados. Tais dados foram tratados descritivamente, com indicação de frequências absolutas e relativas dos núcleos de sentido que se configuraram.

Os ACS foram previamente esclarecidos sobre os objetivos do estudo e convidados a dele participar, sendo assegurado o direito à $\mathrm{AE}$, independentemente de sua participação ou não. Esta pesquisa foi aprovada pelo Comitê de Ética em Pesquisa da Faculdade de Medicina de Botucatu.

\section{Resultados}

A população de estudo caracterizou-se por ser, majoritariamente, composta de mulheres $(88,9 \%)$; jovens, a maioria entre 20 e 30 anos $(57,4 \%)$; com nível de escolaridade médio $(92,6 \%)$, sendo que quatro $(7,4 \%)$ faziam curso superior; $63,0 \%$ tinham filhos e praticamente todos $(97,1 \%)$ tinham experiência pessoal em amamentação (da própria ACS ou da companheira do ACS), com duração variada da amamentação exclusiva destes filhos: $36,4 \%$ até um mês e apenas $9,1 \%$ pelo período recomendado de seis meses.

Quase metade dos ACS $(48,1 \%)$ atuava na ESF há dois anos ou mais e apenas $11,1 \%$ atuavam há seis meses ou menos, sendo o tempo médio de atuação de 27,2 $\pm 17,4$ meses e mediana de 20 meses, com ampla variação: mínimo de um mês incompleto e máximo de 51 meses.

Todos os agentes relataram participação prévia em algum treinamento/curso sobre amamentação, $74,0 \%$ em dois ou mais, sendo que $55,5 \%$ referiram até duas horas e $11,1 \%$ mais de quatro horas como carga horária do maior treinamento. $\mathrm{O}$ tempo médio de treinamento prévio em AM foi de 3,5 $\pm 2,5$ horas, mediana de três horas, mínimo de uma e máximo de 12 horas.

Os resultados relativos às questões de múltipla escolha referentes a conhecimentos antes e depois da $\mathrm{AE}$, após as respostas terem sido categorizadas em adequadas e inadequadas, revelaram que para 16 das 26 questões sobre fisiologia da lactação, recomendações atuais sobre duração do AME, forma de amamentar e manejo do AM, houve aumento significativo $(p<0,05)$ da frequência de respostas adequadas (Tabela 1 ).

Destaca-se o aumento do número de ACS que, após a capacitação, deram respostas adequadas a questões sobre higiene das mamas; desnecessária oferta das duas mamas em toda mamada; medidas para manejo do ingurgitamento; contra-indicação de horários rígidos de mamadas e da oferta de chás para cólicas do lactente; reconhecimento de que a relação mãe/filho influi no sucesso do aleitamento e da importância de familiares e amigos para apoiar a amamentação; diferenças entre leite anterior e posterior e importância das mamadas noturnas, entre outras. Resultado inicial insatisfatório sobre a duração ideal do AM (24 meses ou mais) assim permaneceu: apenas $26(48,1 \%)$ e $31(57,4 \%)$ agentes deram a resposta correta, respectivamente antes e depois da intervenção (Tabela 1).

Para as questões abertas sobre vantagens do AM para mães, vantagens do AM para os bebês, sinais a observar na avaliação de uma mamada, como lidar com ingurgitamento e como lidar com fissuras, todos os ACS deram pelo menos uma resposta adequada, ainda que incompleta.

Promover maior contato mãe-filho foi a mais frequente vantagem do AM para as mães, apontada antes da capacitação; depois desta, auxiliar a contração do útero e reduzir sangramento após o parto. A prevenção de doenças foi a vantagem do AM para a criança mais citada, antes e após a AE, alcançando 83,3\%.

Antes da AE, 79,6\% dos ACS apontaram verificar se a pega está adequada como o ponto mais importante da avaliação de uma mamada, proporção que subiu para $98,1 \%$ após a intervenção. A proporção que referiu ordenhar a mama como a primeira conduta diante do ingurgitamento mamário passou de $57,4 \%$ para $77,7 \%$; no caso de fissuras mamilares, antes da $\mathrm{AE}$, apenas 9,2\% disseram verificar a pega, proporção que subiu para 20,3\%.

Em relação aos resultados da comparação das práticas/ações dos ACS, categorizadas em adequadas e inadequadas à promoção e ao apoio ao $\mathrm{AM}$, antes $\mathrm{e}$ após a capacitação, notaram-se discretas mudanças de frequências (aumentos ou reduções) de respostas adequadas, sem significância estatística. Vale ressaltar que não houve aumento da participação dos ACS em sessões de grupo de gestantes e mães, nem aumentou a proporção de ACS que referiram conversar frequentemente sobre AM com sua equipe. Práticas positivas, como visitar precocemente os recém-nascidos, abordar a amamentação nas visitas domiciliares a gestantes e mães e orientar a prevenção de fissuras, entre outras, foram bastante relatadas antes da capacitação e assim permaneceram. Houve resultado estatisticamente significante somente quanto à troca de informações sobre $\mathrm{AM}$ em grupo de mães, aumentando a freqüência de ACS 
Número e proporção de agentes comunitários de saúde $(n=54)$ que deram respostas adequadas para conhecimento sobre aleitamento materno antes e após ação educativa. Botucatu, SP, 2007.

\begin{tabular}{|c|c|c|c|c|c|}
\hline \multirow[t]{2}{*}{ Questões } & \multicolumn{2}{|c|}{$\begin{array}{c}\text { Respostas adequadas } \\
\text { antes }\end{array}$} & \multicolumn{2}{|c|}{$\begin{array}{c}\text { Respostas adequadas } \\
\text { após }\end{array}$} & \multirow[t]{2}{*}{$p$} \\
\hline & $\mathrm{n}$ & $\%$ & $\mathrm{n}$ & $\%$ & \\
\hline Higiene das mamas & 30 & 55,6 & 47 & 87,0 & $<0,001$ \\
\hline $\begin{array}{l}\text { Inadequação da alternância das mamas durante uma } \\
\text { mamada }\end{array}$ & 29 & 53,7 & 48 & 88,9 & $<0,001$ \\
\hline Inadequação do uso de chupeta & 48 & 88,9 & 52 & 96,3 & 0,141 \\
\hline Medidas para o manejo do ingurgitamento & 22 & 40,7 & 34 & 63,0 & 0,021 \\
\hline Recomendação de tomar sol nas mamas & 50 & 92,6 & 53 & 98,1 & 0,174 \\
\hline Inadequação de horários definidos para amamentar & 36 & 66,7 & 53 & 98,1 & $<0,001$ \\
\hline Como lidar com um bebê com "sinais" de fome & 52 & 96,3 & 54 & 100,0 & 0,153 \\
\hline Diferença entre leite do início e do final da mamada & 40 & 74,1 & 52 & 96,3 & 0,001 \\
\hline Inadequação de chá para cólicas & 44 & 81,5 & 51 & 94,4 & 0,039 \\
\hline Importância da ajuda de pai, avós e vizinhos & 35 & 64,8 & 45 & 83,3 & 0,028 \\
\hline $\begin{array}{l}\text { Relação mãe-bebê não é único condicionante do sucesso } \\
\text { do AM }\end{array}$ & 16 & 28,6 & 32 & 59,3 & 0,002 \\
\hline Aleitamento protege contra problemas ortodônticos & 53 & 98,1 & 53 & 98,1 & 1,000 \\
\hline Frequência e duração das mamadas (livre-demanda) & 40 & 74,1 & 49 & 90,7 & 0,022 \\
\hline Efeitos da pega incorreta sobre a produção de leite & 50 & 92,6 & 49 & 90,7 & 0,721 \\
\hline Efeitos negativos da falta de mamadas noturnas & 31 & 57,4 & 40 & 74,1 & 0,067 \\
\hline $\begin{array}{l}\text { Alimentos consumidos pela mãe não aumentam a } \\
\text { produção de leite }\end{array}$ & 37 & 68,5 & 49 & 90,7 & 0,004 \\
\hline Retirada do leite em excesso favorece produção & 44 & 81,5 & 52 & 96,3 & 0,014 \\
\hline $\begin{array}{l}\text { Oferta de chá e outros líquidos diminuem a produção de } \\
\text { leite }\end{array}$ & 41 & 75,9 & 48 & 88,9 & 0,076 \\
\hline $\begin{array}{l}\text { As mães podem amamentar mesmo não se alimentando } \\
\text { bem }\end{array}$ & 7 & 13,0 & 27 & 50,0 & $<0,001$ \\
\hline Inexistência de leite em pó que substitua a amamentação & 49 & 90,7 & 53 & 98,1 & 0,730 \\
\hline $\begin{array}{l}\text { Quanto tempo após o parto deve-se iniciar a } \\
\text { amamentação }\end{array}$ & 37 & 68,5 & 48 & 88,9 & 0,009 \\
\hline O que fazer com a mama ingurgitada & 30 & 55,6 & 45 & 83,3 & 0,001 \\
\hline O que fazer com fissuras nos mamilos & 27 & 50,0 & 46 & 85,2 & $<0,001$ \\
\hline O que a mãe deve fazer quanto à higiene da mama & 23 & 42,6 & 47 & 87,0 & $<0,001$ \\
\hline Quando o bebê deve receber somente leite materno & 48 & 88,9 & 48 & 88,9 & 0,986 \\
\hline $\begin{array}{l}\text { Até que idade o bebê deve receber leite materno } \\
\text { complementado com outros alimentos }\end{array}$ & 26 & 48,1 & 31 & 57,4 & 0,333 \\
\hline
\end{tabular}


que relataram envolvimento nesta ação de saúde, porém as taxas eram e continuaram muito baixas (Tabela 2).

A Figura 1 apresenta os resultados relativos aos escores de respostas adequadas sobre conhecimentos, práticas e escore total, antes e após a ação educativa. Observaram-se aumentos significativos dos escores médios de conhecimentos $(21,0 \pm 4,5$ para $26,6 \pm 3,19, p<0,001)$ e total $(33,0 \pm 6,52$ para $39,4 \pm 5,05, p<0,001)$.

A comparação das frequências de escores de acertos categorizados em bom, regular e ruim, antes e após a ação educativa, permitiu constatar que houve aumento na proporção de escores de conhecimentos classificados como bons (de 37,0\% para
$88,8 \%, p<0,0001)$ e redução dos escores regulares (de $53,7 \%$ para $9,3 \%, p<0,0001$ ). Em relação ao escore de práticas, não houve mudanças estatisticamente significativas nas proporções de bons, regulares e ruins (dados não mostrados em tabela).

Apresentam-se na Tabela 3 os resultados da avaliação dos efeitos da AE na visão dos ACS. Para a maioria, a intervenção produziu mudanças positivas $(77,7 \%)$, tanto em seus conhecimentos quanto nas práticas relacionadas com oportunidades de promoção e apoio ao AM junto às famílias, inclusive com repercussões percebidas em relação à equipe de saúde e na própria população atendida. Também, a maior parte dos ACS $(92,5 \%)$ relatou mudanças positivas em relação à atuação em AM nas visitas

Tabela 2

Número e proporção de agentes comunitários de saúde $(n=54)$ que deram respostas adequadas sobre práticas relacionadas com oportunidades de promoção e apoio ao aleitamento materno antes e após ação educativa. Botucatu, SP, 2007.

\begin{tabular}{|c|c|c|c|c|c|}
\hline \multirow[t]{2}{*}{ Questões } & \multicolumn{2}{|c|}{$\begin{array}{l}\text { Respostas adequadas } \\
\text { antes }\end{array}$} & \multicolumn{2}{|c|}{$\begin{array}{c}\text { Respostas adequadas } \\
\text { após }\end{array}$} & \multirow[t]{2}{*}{$p$} \\
\hline & $\mathrm{n}$ & $\%$ & $\mathrm{n}$ & $\%$ & \\
\hline Faz visitas às puérperas & 53 & 98,1 & 53 & 98,1 & 1,000 \\
\hline $\begin{array}{l}\text { Realiza a primeira visita até sete dias de vida do recém- } \\
\text { nascido }\end{array}$ & 37 & 68,5 & 40 & 74,1 & 0,520 \\
\hline Orienta sobre aleitamento na primeira visita & 44 & 81,5 & 49 & 90,7 & 0,163 \\
\hline Fala das vantagens e importância do AM para grávidas & 44 & 81,5 & 42 & 77,8 & 0,624 \\
\hline Fala das vantagens e importância do AM de lactentes & 45 & 83,3 & 42 & 77,8 & 0,462 \\
\hline $\begin{array}{l}\text { Pergunta como está o AM nos encontros com mães de } \\
\text { lactentes }\end{array}$ & 48 & 88,9 & 46 & 85,2 & 0,557 \\
\hline Procura ver o bebê mamar durante as visitas & 4 & 7,4 & 8 & 14,8 & 0,220 \\
\hline Orienta possíveis dificuldades com a amamentação & 22 & 40,7 & 29 & 53,7 & 0,176 \\
\hline Consegue explicar às mães como amamentar & 46 & 85,2 & 50 & 92,6 & 0,228 \\
\hline $\begin{array}{l}\text { Orienta sobre manejo do ingurgitamento e fissura } \\
\text { mamária }\end{array}$ & 39 & 72,2 & 39 & 72,2 & 1,000 \\
\hline Participa de grupo de gestantes & 22 & 40,7 & 20 & 37,0 & 0,693 \\
\hline No grupo de gestantes, orienta sobre AM $\left(n=22{ }^{*}\right.$ e $\left.20^{* *}\right)$ & 15 & 68,1 & 15 & 75 & 1,000 \\
\hline Participa de grupo de mães de crianças até dois anos & 14 & 25,9 & 16 & 29,6 & 0,667 \\
\hline No grupo de mães, orienta sobre AM $\left(n=14^{*}\right.$ e $\left.16^{* *}\right)$ & 5 & 35,7 & 10 & 62,5 & 0,167 \\
\hline $\begin{array}{l}\text { Mães trocam informações sobre AM no grupo }\left(n=14^{*} e\right. \\
\left.16^{* *}\right)\end{array}$ & 1 & 7,1 & 7 & 43,7 & 0,028 \\
\hline A equipe fala sobre aleitamento materno & 5 & 9,3 & 6 & 11,1 & 0,757 \\
\hline
\end{tabular}

$\mathrm{AM}=$ aleitamento materno; * total para esta questão antes da ação educativa; ** total para essa questão após a ação educativa. 
Média, mediana, valor mínimo e máximo dos escores de acertos de conhecimentos, práticas e totais obtidos por agentes comunitários de saúde $(n=54)$ antes e após ação educativa sobre aleitamento materno. Botucatu, SP, 2007.

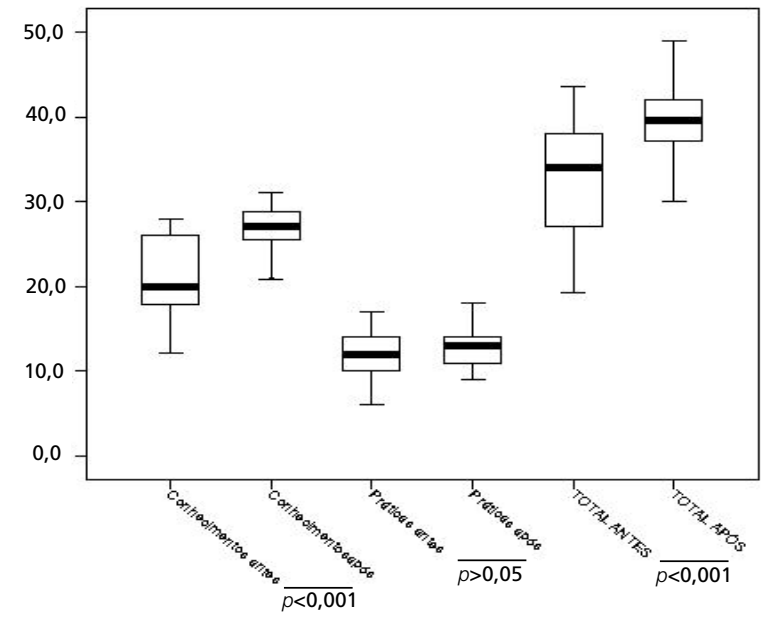

Tabela 3

Distribuição dos agentes comunitários da saúde $(n=54)$ em relação aos efeitos da ação educativa sobre sua atuação na equipe multiprofissional e em visitas domiciliarias. Botucatu, SP, 2007.

Efeitos da ação educativa sobre:

Trabalho em equipe

Ampliação da participação/aceitação no trabalho em equipe

Aquisição/acréscimo de conhecimentos/experiências

Aumento de confiança/segurança

Alinhamento conceitual e prático em relação à equipe

Mudou pouco ou nada mudou em relação à equipe

Não sabe se mudou

Sem resposta

Total

Visita domiciliar

Aumento na quantidade e qualidade das orientações

Aumento da segurança em orientar

Melhora na forma de abordar as gestantes e mães

Mudança de comportamento das mães (segurança e relactação)

Mudou pouco ou nada mudou nas visitas domiciliárias

Sem resposta

Total
N

$\%$

9,3

18,5

1,9

1,9

100,0

54

53,7

24,0

14,8

3,7

1,9

1,9

100,0 
domiciliares (Tabela 3).

\section{Discussão}

A avaliação realizada antes da $\mathrm{AE}$ indicou que vários aspectos adequados de conhecimento sobre AM estavam presentes. Os ACS estudados já reconheciam a importância e várias vantagens do AM, principalmente para a saúde infantil, mas tinham conhecimentos insuficientes sobre manejo do aleitamento, tanto da avaliação da mamada, quanto da prevenção e cuidados com intercorrências comuns no início do AM, entre outros. Ao mesmo tempo, apresentavam pouco envolvimento com práticas relacionadas à promoção do $\mathrm{AM}$, resultados esses semelhantes aos observados em outras categorias de profissionais da equipe de saúde da família por Ciconi et al. 14 em São Paulo e por Caldeira et al. 18 em Minas Gerais.

Este achado inicial coincide com relatos de participação prévia dos ACS em ações educativas sobre AM, a maioria de curta duração (duas horas). Vale ressaltar que não havia na Secretaria Municipal de Saúde do município qualquer registro formal de capacitação sobre AM envolvendo ACS, mas foi possível apurar que ocorreram iniciativas internas às equipes de saúde da família onde atuavam.

Considerando os resultados previamente esperados com a $\mathrm{AE}$ e os detectados após sua implementação, para questões sobre conhecimentos, em que $75 \%$ ou mais dos ACS apontaram respostas adequadas antes da $\mathrm{AE}$, houve alguma melhora após a intervenção, mas as diferenças, pequenas, não alcançaram significância estatística. Esse foi o caso de conhecimentos sobre o uso inadequado de chupeta, sinais de fome no bebê, contra indicação de chá para cólicas, entre outros. Tais tópicos não foram priorizados na intervenção, dado o menor número de agentes que responderam incorretamente sobre eles na avaliação pré $\mathrm{AE}$, em comparação com outros tópicos. Assim, a intervenção não foi capaz de alterar as respostas de agentes que, possivelmente, divergiam e não apenas desconheciam as recomendações atuais relativas a estes tópicos. Particularmente, as opiniões sobre o uso de chás e de chupeta no cuidado de recém-nascidos e lactentes, pelo seu caráter cultural e simbólico, são de difícil transformação. 19

Para um segundo grupo de conhecimentos, cuja frequência inicial de respostas adequadas foi regular ( $\geq 50 \%$ e $<75 \%$ ), houve aumento de maior magnitude na frequência de respostas corretas. Esse efeito foi observado para itens como: higiene das mamas, troca das mamas durante a mamada, regime e duração das mamadas, mamadas noturnas e como lidar com ingurgitamento e fissuras. Estes tópicos envolvem aspectos técnicos do manejo da amamentação que foram bastante abordados na intervenção. A capacitação em manejo da amamentação tem sido consi-derada necessária para o impacto positivo do trabalho de equipes de saúde da família em apoio ao aleitamento materno. ${ }^{14,18,20}$

Com relação a um terceiro grupo de conhecimentos, cuja frequência de ACS que responderam adequadamente na avaliação pré-intervenção foi menor do que $50 \%$, houve mudanças positivas ainda mais relevantes. Nesta situação, enquadram-se conhecimentos sobre a importância da relação mãe/filho para o sucesso do aleitamento e conhecimentos pertinentes sobre a relação entre alimentação materna e produção de leite, indicando que, de modo geral, sob a ótica da situação inicial e dos aspectos priorizados, os resultados obtidos, tanto os positivos quanto os negativos, parecem decorrer da ação educativa implementada.

Como resultado divergente, destaca-se que não houve melhora na frequência de agentes que apontaram corretamente 24 meses ou mais como a duração recomendada do AM: a situação inicial era muito negativa e assim continuou, indicando tratarse de tema a envolver mais do que acesso à informação correta. Possivelmente, os ACS não "aceitem" ou não "reconheçam" a legitimidade da recomendação de duração do AM vigente, cabendo a futuros estudos de natureza qualitativa compreender esse fenômeno.

Com relação à participação dos ACS em práticas relacionadas com oportunidades de promoção e apoio ao AM, os resultados indicaram que, no caso daquelas já referidas por grande número de agentes na primeira avaliação $(\geq 75 \%)$, como visitar puérperas e orientar a amamentação na visita ao recémnascido, não houve mudanças após a AE. Para práticas desejáveis cuja frequência inicial era apenas regular ( $\geq 50 \% \mathrm{e}<75 \%$ ), também não houve efeitos positivos. Apenas para práticas desejáveis com frequência muito baixa na primeira avaliação (< $50 \%$ ), como no caso da participação ativa dos ACS em grupos de gestantes e mães, houve alguns efeitos positivos, mas as frequências após a ação educativa conti-nuaram muito insatisfatórias. Deve-se lembrar que a intervenção não incluiu atividades específicas para capacitar os ACS para trabalho de grupo com gestantes, o que constituiu uma lacuna importante da intervenção realizada, considerando que este tipo de ação de saúde tem sido apontado como bastante efetivo na promoção do aleitamento materno. 20

Outra limitação do presente estudo se refere à 
opção por grupo controle histórico, impedindo a avaliação do impacto da intervenção, ${ }^{21}$ tanto sobre o desempenho dos ACS, quanto sobre as taxas de aleitamento na população assistida. Esta opção decorreu da dificuldade de se manter um grupo controle sem que seus membros compartilhassem as informações e conteúdos com membros que estivessem participando da AE. Mesmo com esta limitação, a implicação da $\mathrm{AE}$ nos resultados observados parece clara, devido a estes terem variado conforme a priorização dos tópicos, à adequação da mesma quanto às estratégias de ensino e referenciais pedagógicos já validados e à existência de resultados efetivos de intervenções semelhantes, inclusive com profissionais sem formação na área da saúde e com leigos, categorias próximas da situação dos ACS participantes deste estudo.22-24 Também, é importante apontar que no período entre a intervenção e sua avaliação não houve qualquer outra intervenção educacional ou de promoção ao AM no município, quer dirigida aos profissionais de saúde, quer à população em geral, permitindo que de fato a situação inicial dos conhecimentos e práticas dos agentes atuasse como um controle interno histórico.

Porém, mesmo buscando adotar técnicas de ensino-aprendizagem consideradas facilitadoras da transformação da realidade dos profissionais de saúde, $8,25,26$ não houve aumento da participação dos ACS nas práticas/ações como se esperava. Tal resultado pode ser atribuído, em parte, às condições de implementação das práticas avaliadas. Tais condições se relacionam à possível falta de governabilidade dos ACS para introduzir/alterar ações, condutas e rotinas do serviço de saúde, além de um provável descompasso entre os ACS que vivenciaram esta experiência integralmente e os demais profissionais da equipe, no que se refere à sensibilização para a priorização da promoção e apoio ao AM. Houve apenas a participação dos enfermeiros em uma atividade, no dia do encerramento, quando foram pactuadas as ações que seriam mantidas/implementadas, fato que se revelou a principal fragilidade desta $\mathrm{AE}$, no que se refere à sensibilização para a priorização da promoção e apoio ao AM. Suporta esta recomendação estudo sobre a capa-citação de agentes de saúde no município de Campinas/SP, que identificou o fato de os agentes terem sido envolvidos no processo educativo sem os demais membros da equipe de saúde como potencializador da dificuldade de sua inserção nas equipes. 27

Pode-se questionar, também, se houve tempo suficiente para mudanças nas práticas dos ACS, pois os dados após intervenção foram coletados dois meses após o encerramento da AE. Os resultados da avaliação da intervenção na ótica dos ACS falam a favor desta hipótese, pois revelaram que para além das mudanças alcançadas em seus saberes técnicos, esses profissionais tiveram a oportunidade de rever (pré) conceitos e adequar posturas, o que se configura como fator primordial que pode contribuir para o movimento mais amplo em direção à promoção e apoio ao AM.

Conclui-se que a intervenção - ação educativa de cunho teórico-prático, com 32 horas, focada na solução de problemas/dificuldades vividos pelas mães e reportados/percebidos aos/pelos ACS no cotidiano do trabalho - proporcionou aumento da proporção de ACS com conhecimentos adequados sobre aleitamento materno e da segurança desses profissionais para atuar junto às famílias, em sua promoção e apoio. Porém, não resultou em mudanças nos índices de participação dos ACS em algumas das ações/práticas de saúde consideradas efetivas para aumentar as taxas de AM, recomendando-se maior ênfase na capacitação para trabalho com gestantes e com grupos e a inclusão de gestores e demais membros da equipe de saúde da família em ações educativas futuras.

\section{Referências}

1. Sena MCF, Silva EF, Pereira MG. Tendência do aleitamento materno no Brasil no último quarto do século XX. Rev Bras Epidemiol. 2007; 10: 499-505.

2. Réa MF. Reflexões sobre a amamentação no Brasil: de como passamos a 10 meses de duração. Cad Saúde Pública. 2003; 19 (Supl 1): S37-S45.

3. Oliveira MIC, Camacho LAB, Souza IEO. Promoção, proteção e apoio à amamentação na atenção primária à saúde no estado do Rio de Janeiro, Brasil: uma política de saúde pública baseada em evidência. Cad Saúde Pública. 2005; 21: 1901-10.
4. Brasil. Ministério da Saúde. Departamento de Atenção Básica. Política Nacional de Atenção Básica. 4 ed. Brasília, DF; 2007.

5. Brasil. Ministério da Saúde. Secretaria de Políticas de Saúde. Departamento de Atenção Básica. Instituto Materno Infantil de Pernambuco. Atenção básica à saúde da criança; texto de apoio para o agente comunitário da saúde. Brasília, DF; 2001.

6. Brasil. Lei n.11.350, de 05 de outubro de 2006. Regulamenta o §5o do art. 198 da Constituição, dispõe sobre o aproveitamento de pessoal amparado pelo parágrafo 
único do art. 2o da Emenda Constitucional no 51, de 14 de fevereiro de 2006, e dá outras providências. Diário Oficial da União, Brasília, DF; 06 out 2006. Seção 1, p. 1.

7. Caldeira AP, Fagundes GC, Aguiar GN. Intervenção educacional em equipes do Programa de Saúde da Família para promoção da amamentação. Rev Saúde Pública. 2008; 42: 1027-33.

8. Brasil. Ministério da Saúde. Secretaria de Atenção à Saúde Departamentos de Ações Programáticas Estratégicas. Área Técnica da saúde da Criança e Aleitamento Materno. Departamento de Atenção Básica. Rede Amamenta Brasil: caderno do tutor. Brasília, DF; 2009.

9. Delors J. Educação: um tesouro a descobrir. Relatório para a UNESCO da Comissão Internacional sobre Educação para o século XXI. 6 ed. São Paulo: Cortez; 2001.

10. Freire P. Pedagogia da autonomia: saberes necessários à prática Educativa. 33 ed. São Paulo: Paz e Terra. 2006; 148 p.

11. FIBGE (Fundação Instituto Brasileiro de Geografia e Estatística). [Citado em 2008 jul 04] Disponível em http://www.ibge.gov.br/cidadesat/topwindow.htm.

12. Ferreira L, Parada CMGL, Carvalhaes MABL. Tendência do aleitamento materno em município da região centro-sul do estado de São Paulo: 1995-1999-2004. Rev Nutr. 2007; 20: 265-73.

13. Becker D. No seio da família: amamentação e promoção da saúde no programa de saúde da família [dissertação]. Rio de Janeiro: Escola Nacional de Saúde Pública da Fundação Oswaldo Cruz; 2001

14. Ciconi RCVC, Venâncio SI, Escuder MML. Avaliação dos conhecimentos de equipes do programa saúde da família sobre o manejo do aleitamento materno em um município da região metropolitana de São Paulo. Rev Bras Saúde Mater Infant. 2004; 4: 193-202

15. Brasil. Ministério da Saúde/UNICEF. Manejo e promoção do aleitamento materno: curso de 18 horas para equipes de maternidade. Brasília, DF; 1993.

16. WHO (World Health Organization). Breastfeeding counseling: a training course. Geneva; 1994. WHO/CDR/93.3-6 (UNICEF/NUT/93.1-4) Available upon request from Health Systems and Community Health , World Health Organization, 1211 Geneva 27, Switzerland.

Recebido em 27 de novembro de 2009

Versão final apresentada em 20 de agosto de 2010

Aprovado em 6 de setembro de 2010
17. Bardin L. Análise de conteúdo. 3 ed. Lisboa: Edições 70; 2004

18. Caldeira AP, Aguiar GN, Magalhães WAC, Fagundes GC. Conhecimentos e práticas de promoção do aleitamento materno em equipes de saúde da família de Montes Claros, Minas Gerais, Brasil. Cad Saúde Pública. 2007; 23: 196570

19. Parizoto GM, Parada CMG, Venâncio SI, Carvalhaes MABL. Tendência e determinantes do aleitamento materno exclusivo em crianças menores de seis meses. J Pediatr. 2009; 85: 201-8.

20. Oliveira MIC, Camacho LAB, Tedstone AE. Extending breastfeeding duration through primary care: a systematic review of prenatal and postnatal interventions. J Hum Lact. 2001; 17: 326-43.

21. Santos IS, Victora CG. Serviços de saúde: epidemiologia, pesquisa e avaliação. Cad Saúde Pública. 2004; 20 (Sup1 2): S337-S41.

22. Réa MF, Venâncio SI, Martines JC, Savage F. Counselling on breastfeeding: assessing knowledge and skills. Bull of the World Health Organ. 1999; 77: 492-8.

23. Coutinho SB, Lima MC, Ashworth A, Lira PIC. Impacto de treinamento baseado na Iniciativa Hospital Amigo da Criança sobre práticas relacionadas à amamentação no interior do Nordeste. J Pediatr. 2005; 81: 471-7.

24. Armstrong HC. Breastfeeding promotion: training of midlevel and outreach health workers. Int J Gynaecol Obstet. 1990; 31 (Supl 1): 91-104.

25. Britton C, MacCormick FM, Renfrew MJ, Wade A, Keng SE. Support for breastfeeding mothers. Cochrane Database Syst Rev. 2008; 2.

26. O'Brien MA, Freemantle N, Oxman AD, Wolf F, Davis DA, Herrin J. Continuing education meetings and workshops: effects on professional practices and health care outcomes Cochrane Database Syst Rev. 2007; 4.

27. Nascimento EPL, Corrêa CRS. O agente comunitário de saúde: formação, inserção e práticas. Cad Saúde Pública. 2008; 24: 1304-13. 